\title{
Traffic simulation of Beijing West railway station North area
}

\author{
Xiaochun Lu, Zhanping Liu \\ Beïing Jiaotong University (China) \\ xclu@,bjtu.edu.cn; 11120658@,bjtu.edu.cn
}

Received: October 2012

Accepted: March 2013

\section{Abstract:}

Purpose: In recent years the problem of traffic congestion and its management has become increasingly prominent. It is a hot research about how to make full use of computer simulation technology to make transportation more rational and more organized. In this paper, we focus on traffic of Beijing West Railway Station north area, and try to find a way to reduce traffic congestion in this area.

Approach: In this paper, we studied the traffic flow by survey. We also built a traffic simulation model with VISSIM software. Different types of vehicles and their speed are set in model according survey data. The simulation model provides different traffic scenarios of Beijing West Railway Station north area.

Findings: We found the traffic of this area up is to 1800 vehicles/hour. Heavy traffic burden causes traffic congestion in two positions: the bus hub and car drop-off point. If we can extend bus interval departure time and park cars to south square of Beijing West Railway Station, the traffic condition will be improved.

Originality: This paper gives a solution to reduce traffic congestion in Beijing West Railway Station north area. The bus hub and car parking lots are the key point of traffic problem in this area.

Keywords: traffic simulation, Beijing West Railway Station, VISSIM 


\section{Introduction}

Traffic simulation models can represent real-world conditions such as delays, travel times, queues, and flows. This technology is becoming an increasingly important tool for transport system analysis and management. The applications of VISSIM simulation are increasingly developed today as potential solutions to traffic problems.

VISSIM is commonly used software in practice for diverse problems related to road traffic control. It is based on psycho-physical driving algorithms and can reflect the reality of the problem more accurately. Cunto assumed that individual driver safety performance provides a fundamental indication for crash risk and suggested a systematic and objective procedure for specifying model inputs based on driver safety performance measures for rear-end crashes at signalized intersections with VISSIM (Cunto \& Saccomanno, 2008). Bains evaluated capacity of expressways and studied the effect of vehicle composition on Passenger Car Unit (PCU) values by modeling traffic flow on Indian expressways (Bains, Ponnu \& Arkatkar, 2012). Ahmed evaluated indirect right turn treatment to reduce conflicts and congestion at signalized intersections in urban areas and VISSIM was used to evaluate before and after scenarios (Ahmed, 2011). Qiu evaluated the road congestion condition by VISSIM and put forward some measures to improve urban road congestion condition (Qiu \& Zheng, 2011). Du used VISSIM to simulate the traffic phenomenon, and in-depth analysis of traffic flow characteristics, taking Jintong West Rd-Jinghua North Street Crossroads as an example. Through the simulation of observation, this paper got the simulation output parameters and basic characteristics of the intersection, and in-depth researched the critical causes of congestion, and put forward the corresponding improving countermeasures (Du \& Liu, 2012).

Previous simulation studies have examined different lane-restriction strategies for heavy vehicles, but, the general lane-changing model ignore the fundamental differences in the lanechanging behavior of passenger cars and heavy vehicles which can increase the accuracy of simulation models. However, an exclusive lane-changing model for heavy vehicles can increase the accuracy of simulation models, verified by Moridpour (Moridpour \& Mazloumi, 2011).

As technology advances, the combination of VISSIM and algorithm has been widely studied for solving practical problems. Liu proposed a procedure, based on a genetic algorithm, to model U-turn movements at unsignalized intersections with nontraversable median cross sections in the traffic simulation program VISSIM. The simulation results were estimated using gap acceptance models, which showed VISSIM provides reasonable capacity estimates for U-turns at unsignalized intersections (Liu \& Qu, 2012). Stevanovic presented a GA program which is described as VISSIM-based Genetic Algorithm Optimization of Signal Timings (VISGAOST) and he optimized traffic signal timings for both transit and private modes. The evaluation of VISGAOST showed VISGAOST can be used as a practical tool for the optimizations of signal timings, performed on two test-case networks (Stevanovic \& Stevanovic, 2008). Existing 
studies for Variable Speed Limit (VSL) algorithms have considered only one station to control the traffic. Jo proposed an optimization model of VSL for multiple stations, performed by VISSIM. The results show that the proposed algorithm improves safety on roads with minimum additional travel time (Jo \& Kim, 2012). Besides, Tamas proposed MATLAB may be involved in the traffic simulation to create an integrated environment with VISSIM. Thus, complex mathematical problems can be calculated online by MATLAB and used for VISSIM simulation (Tettamanti \& Varga, 2012).

Based on the survey of the traffic flow around Beijing West Railway Station north area, we programed traffic simulation to find out the causes of traffic congestion and provide some optimization proposals with VISSIM.

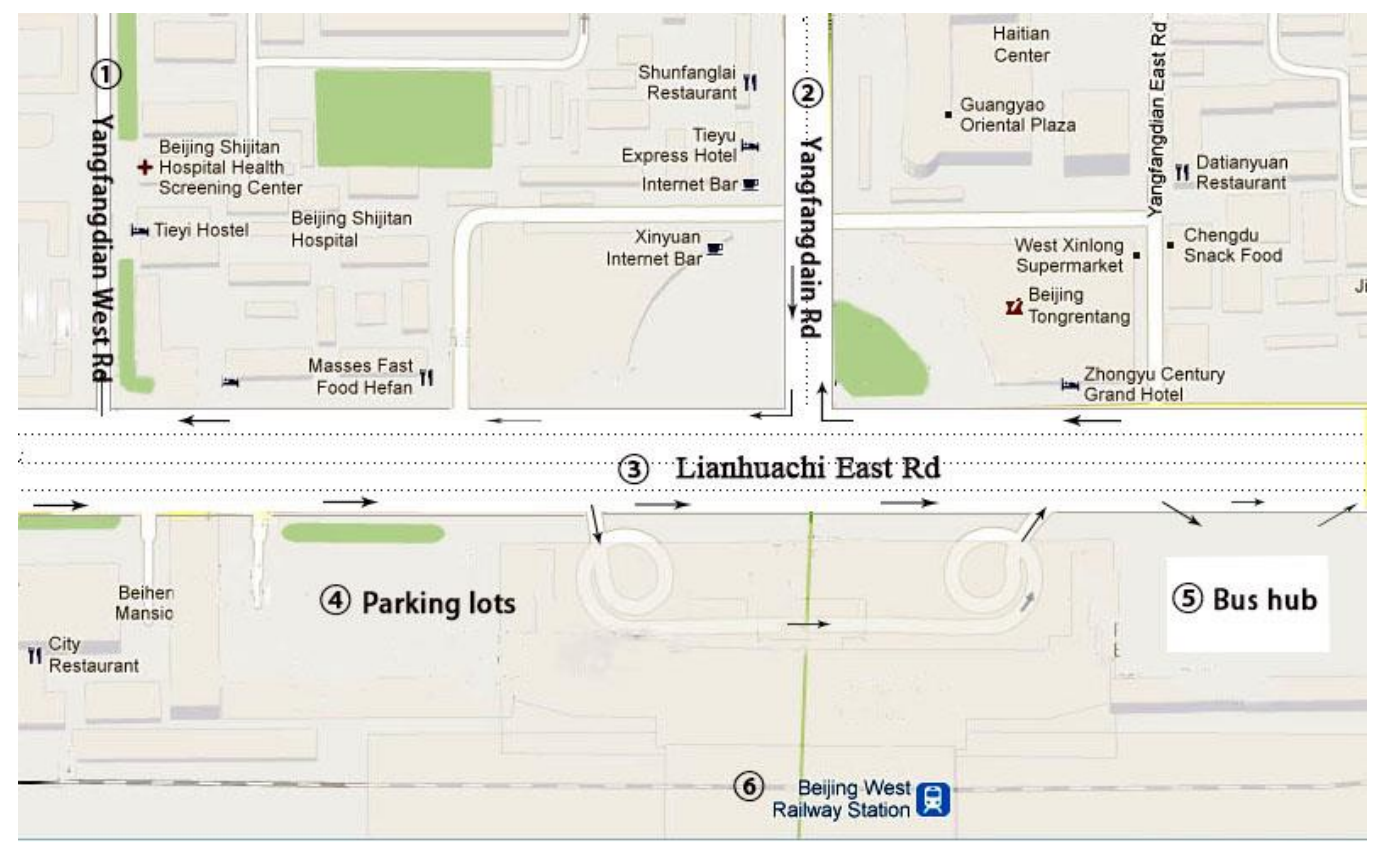

1) Yangfangdian West Rd. 2) Yangfangdian Rd. 3) Lianhuachi East Rd.

4) Parking lots 5) Bus hub 6) Beijing West Railway Station

Figure 1. Beijing West Railway Station north area map

This paper is structured as follows: The next section provides the analysis of traffic situation and underlying data around Beijing West Railway Station north area. The following section is about establishing the simulation model. The last section analysis simulation results, summarizes the findings and conclusions.

\section{Traffic situation and underlying data analysis}

Beijing West Railway Station and surrounding transportation system is shown as Fig. 1. There are 3 main roads in this area: Yangfangdian East Road, Yangfangdian Road and Lianhuachi East Road. In addition, a bus hub is on the east of railway station. A large number of buses, cars and taxis are driving in front of Beijing West Railway station. 


\subsection{Traffic situation}

The survey data of traffic flow are shown in Table 1. From table 1, we can see that vehicles mainly are cars. They are over $83 \%$. Buses are about $15 \%$ 4\%.

\begin{tabular}{|c|c|c|c|c|}
\hline \multirow{2}{*}{ Location } & \multirow{2}{*}{$\begin{array}{l}\text { Vehicle } \\
\text { Type }\end{array}$} & \multicolumn{2}{|c|}{ Quantity (in vehicles) } & \multirow{2}{*}{$\begin{array}{c}\text { Proportion } \\
(\%)\end{array}$} \\
\hline & & Time 9:30-11:30 & Time $16: 30-17: 30$ & \\
\hline \multirow{4}{*}{$\begin{array}{l}\text { Lianhuachi } \\
\text { East Rd from } \\
\text { east to west }\end{array}$} & car & 3010 & 1532 & 83.8 \\
\hline & bus & 564 & 269 & 15.369 \\
\hline & van & 35 & 10 & 0.83 \\
\hline & total & 3609 & 1811 & 100 \\
\hline \multirow{4}{*}{$\begin{array}{l}\text { Lianhuachi } \\
\text { East Rd from } \\
\text { west to east }\end{array}$} & car & 3617 & 1755 & 83.8 \\
\hline & bus & 665 & 322 & 15.369 \\
\hline & van & 36 & 17 & 0.83 \\
\hline & total & 4316 & 2094 & 100 \\
\hline \multirow{4}{*}{$\begin{array}{c}\text { Yangfangdian } \\
\text { Rd }\end{array}$} & car & 800 & 401 & 86.903 \\
\hline & bus & 84 & 43 & 9.19 \\
\hline & van & 31 & 23 & 3.907 \\
\hline & total & 915 & 467 & 100 \\
\hline \multirow{4}{*}{$\begin{array}{c}\text { Yangfangdian } \\
\text { West Rd }\end{array}$} & car & 574 & 328 & 94.947 \\
\hline & bus & 30 & 8 & 4 \\
\hline & van & 9 & 1 & 1.053 \\
\hline & total & 613 & 337 & 100 \\
\hline
\end{tabular}

Table 1. The Survey Data of Traffic Flow in Beijing West Railway Station north area

\subsection{Bus and taxi dwelling time}

In Beijing West Railway Station area, only can taxi and bus provide public transportation service. We found that when a taxi drops off passengers and a bus drives away from bus hub will cause traffic jam. In order to build simulation model, we must give out random distribution of bus departure time and taxi dwelling time as well.

In bus hub, a bus should depart according schedule. However, we found that a bus departure time depends on arriving and waiting passengers. A bus interval departure time varies from 8 minutes to 10 minutes, obeying uniform distribution. Besides, a bus dwelling time (waiting for passengers boarding) is subject to triangle distribution $(1,5,6)$ minutes.

A lot of taxies often drop off passengers by waiting hall. Its dwelling time has more obvious characteristics: during the traffic peak period, average dwelling time is about 30 seconds, however in the non-peak traffic, the dwelling time is irregular. In this paper we use 30 seconds as its dwelling time.

\subsection{Distribution of traffic arrival rate}

Around the Beijing West Railway Station north area, traffic flow concerns about Lianhuachi East Rd, Yangfangdian Rd, Yangfangdian East Rd, Yangfangdian West Rd and the bus hub. In VISSIM software, we can set traffic flow as different time intervals, and then program will generate vehicles according proportion we have given out. We counted vehicles every 5 minutes in Beijing West Railway Station and got survey results shown as in Table 2. 


\begin{tabular}{|c|r|r|}
\hline \multirow{2}{*}{ Location } & \multicolumn{3}{|c|}{ Traffic Arrival Rate (vehicles/ hour) } \\
\cline { 2 - 3 } & Time 9:30-11:30 & Time 16:30-17:30 \\
\hline Lianhuachi East Rd from east to west & 1804 & 1811 \\
\hline Lianhuachi East Rd from west to east & 2158 & 2094 \\
\hline Yangfangdian Rd & 458 & 467 \\
\hline Yangfangdian West Rd & 307 & 337 \\
\hline
\end{tabular}

Table 2. Traffic Arrival Rate

In VISSIM, buses running lane needs to be set separately on account of buses must stop at bus station. In case of no traffic jams, a bus almost runs in accordance with its schedule strictly.

\subsection{Path decision data}

\begin{tabular}{|c|c|c|c|}
\hline \multicolumn{2}{|c|}{ Path and Path Decision } & Vehicle Type & Quantity (in vehicles) \\
\hline \multirow{6}{*}{$\begin{array}{c}\text { From Lianhuachi East } \\
\text { Rd to Yangfangdian } \\
\text { Rd }\end{array}$} & \multirow{3}{*}{$\begin{array}{c}\text { Go straight on Lianhuachi } \\
\text { East Rd }\end{array}$} & cars & 4042 \\
\hline & & buses & 743 \\
\hline & & vans & 39 \\
\hline & \multirow{3}{*}{$\begin{array}{l}\text { Turn right to the } \\
\text { Yangfangdian Rd }\end{array}$} & cars & 800 \\
\hline & & buses & 84 \\
\hline & & vans & 31 \\
\hline \multirow{2}{*}{$\begin{array}{l}\text { from Lianhuachi East } \\
\text { Rd to XiMuLou } \\
\text { Community }\end{array}$} & $\begin{array}{c}\text { Go straight on Lianhuachi } \\
\text { East Rd }\end{array}$ & \multirow{2}{*}{ all } & 100 \\
\hline & $\begin{array}{l}\text { Turn right to XiMuLou } \\
\text { Community }\end{array}$ & & 1 \\
\hline \multirow{6}{*}{$\begin{array}{c}\text { From Lianhuachi East } \\
\text { Rd to Yangfangdian } \\
\text { West Rd }\end{array}$} & \multirow{3}{*}{$\begin{array}{c}\text { Go straight on Lianhuachi } \\
\text { East Rd }\end{array}$} & cars & 3990 \\
\hline & & buses & 733 \\
\hline & & vans & 38 \\
\hline & \multirow{3}{*}{$\begin{array}{l}\text { Turn right to the } \\
\text { Yangfangdian West Rd }\end{array}$} & cars & 574 \\
\hline & & buses & 30 \\
\hline & & vans & 7 \\
\hline \multirow{2}{*}{$\begin{array}{l}\text { From Lianhuachi East } \\
\text { Rd to the parking lot }\end{array}$} & $\begin{array}{l}\text { Go straight along } \\
\text { Lianhuachi East Rd }\end{array}$ & \multirow{2}{*}{ cars } & 6410 \\
\hline & $\begin{array}{l}\text { Turn right to the parking } \\
\text { lot }\end{array}$ & & 817 \\
\hline \multirow{9}{*}{$\begin{array}{l}\text { From Lianhuachi East } \\
\text { Rd to the waiting hall }\end{array}$} & \multirow{3}{*}{$\begin{array}{l}\text { Go straight along } \\
\text { Lianhuachi East Rd }\end{array}$} & cars & 5371 \\
\hline & & buses & 980 \\
\hline & & vans & 53 \\
\hline & \multirow{3}{*}{$\begin{array}{l}\text { Turn right to the } \\
\text { underground parking }\end{array}$} & cars & 527 \\
\hline & & buses & 0 \\
\hline & & vans & 0 \\
\hline & \multirow{3}{*}{$\begin{array}{c}\text { Turn right to the waiting } \\
\text { hall }\end{array}$} & cars & 2237 \\
\hline & & buses & 0 \\
\hline & & vans & 0 \\
\hline
\end{tabular}

Table 3. Path Decision Data

Traffic flow in Lianhuachi East Rd may turn right or make a U-turn, so vehicles will make path decisions. In VISSIM software, driving path decisions are made according to different mode in a different ratio. For example, a part of cars from Lianhuachi East Rd maybe turn to right to Yangfangdian Rd, other cars maybe go ahead. In simulation program, we must set vehicles' path decision. The path decision in this paper is shown in Table 3. 


\section{Simulation modeling}

\subsection{Modeling road network}

In order to build a precise road network model complying with the actual in VISSIM, we import Beijing West Railway Station map from Google earth as background picture. After that, we build road network in proportion. Besides, as mentioned previously, bus lane has been created separately and bus stop has been set up in the corresponding.

\subsection{Modeling traffic flow}

\begin{tabular}{|c|r|r|r|}
\hline Time(sec) & 0-3600(s) & \multicolumn{1}{|c|}{$3600-7200(\mathrm{~s})$} & $7200-10800(\mathrm{~s})$ \\
\hline $\begin{array}{c}\text { Road } \\
\text { Lianhuachi East Rd from east to } \\
\text { west(north traffic flow) }\end{array}$ & 1804 & 1804 & 1811 \\
\hline $\begin{array}{c}\text { Yangfangdian Rd } \\
\text { Yangfangdian West Rd }\end{array}$ & 458 & 458 & 467 \\
\hline $\begin{array}{c}\text { Lianhuachi East Rd from west to } \\
\text { east(south traffic flow) }\end{array}$ & 2158 & 2158 & 337 \\
\hline
\end{tabular}

Table 4. The Traffic Flow in Different Periods

In VISSIM, the traffic flow model consists of two parameters: the traffic flow in different routes and the traffic flow in different periods in the same route. The traffic flow in different periods is given out in Table 4. From Table 4, we can find that the south traffic flow is larger than the north. The traffic burden of Lianhuachi East Road from west to east is higher than this road from east to west.

\subsection{Vehicle priority rules}

At the intersection of no signal control, VISSIM uses priority rules specify the road right in vehicles conflicting scenarios. In our model, the rule is that cars going ahead are prior to the rest on the main road, and cars going straightly are ahead of turning ones.

\section{Simulation results analysis}

We evaluate the traffic system from two aspects: indicators that reflect fluency such as vehicle average queue length, maximum queue length, the total number of vehicles in queue; indicators that reflect efficiency such as average delay time, average stopping time, average travel time, times of stops.

According to the simulation results, except the two intersections mentioned below, the traffic congestion around Beijing West Railway Station north area is not so serious. 


\begin{tabular}{|r|r|r|r|}
\hline Interval Time(sec) & Travel Time (sec) & Average Delay Time(sec) & Block Time(sec) \\
\hline 900 & 53.3 & 10.8 & 1.1 \\
\hline 1800 & 51.3 & 8.7 & 0.6 \\
\hline 2700 & 55.6 & 12.5 & 1.8 \\
\hline 3600 & 57.8 & 15 & 2.7 \\
\hline 4500 & 52.1 & 9.4 & 0.9 \\
\hline 5400 & 67.8 & 25.4 & 4.2 \\
\hline 6300 & 70.2 & 27.4 & 7.5 \\
\hline 7200 & 56.3 & 13.8 & 1.7 \\
\hline 8100 & 52.9 & 9.7 & 1.3 \\
\hline 9000 & 71.7 & 29.2 & 9.6 \\
\hline 9900 & 78.6 & 35.9 & 9 \\
\hline 10800 & 49.6 & 6.8 & 0.4 \\
\hline
\end{tabular}

Table 5. Itinerary and Delay Time Statistics at the $1^{\text {st }}$ Congestion Position

\begin{tabular}{|r|r|r|r|}
\hline Interval Time (sec) & Queue Avg. Len. (meters) & Queue Max. Len.(meters) & Delay Time(sec) \\
\hline 900 & 26 & 149 & 292 \\
\hline 1800 & 22 & 119 & 286 \\
\hline 2700 & 34 & 179 & 361 \\
\hline 3600 & 43 & 168 & 534 \\
\hline 4500 & 22 & 135 & 318 \\
\hline 5400 & 79 & 256 & 737 \\
\hline 6300 & 89 & 285 & 828 \\
\hline 7200 & 40 & 168 & 509 \\
\hline 8100 & 21 & 129 & 256 \\
\hline 9000 & 89 & 250 & 753 \\
\hline 9900 & 102 & 301 & 760 \\
\hline 10800 & 13 & 160 & 203 \\
\hline
\end{tabular}

Table 6. Vehicles Queue Statistics at the $1^{\text {st }}$ Congestion Position

\subsection{The first congestion point}

By simulation, we found that vehicles will be blocked at the intersection of Lianhuachi East Rd and the waiting hall. The congestion position is shown in Fig.2, which is illustrated by circle. Simulation results are shown in Table 5 and Table 6.

As we can see from Table 5 and Table 6, vehicles' average delay time is 6 to 27 seconds and queue average length is from 22 to 102 meters. Maximum length of vehicles queue is generally over 110 meters and the maximum can be up to 300 meters. The highest delay time may reaches 800 seconds.

The main factor is that a large number of cars turn right to drop of passenger by waiting hall which is on the Beijing West Railway Station second floor. So it causes congestion.

\subsection{The second congestion point}

By simulation, we found the second congestion point which lays the intersection of Lianhuachi East Road and bus hub, as shown circle in Fig. 3. Simulation results are shown in Table 6 and Table 7. 


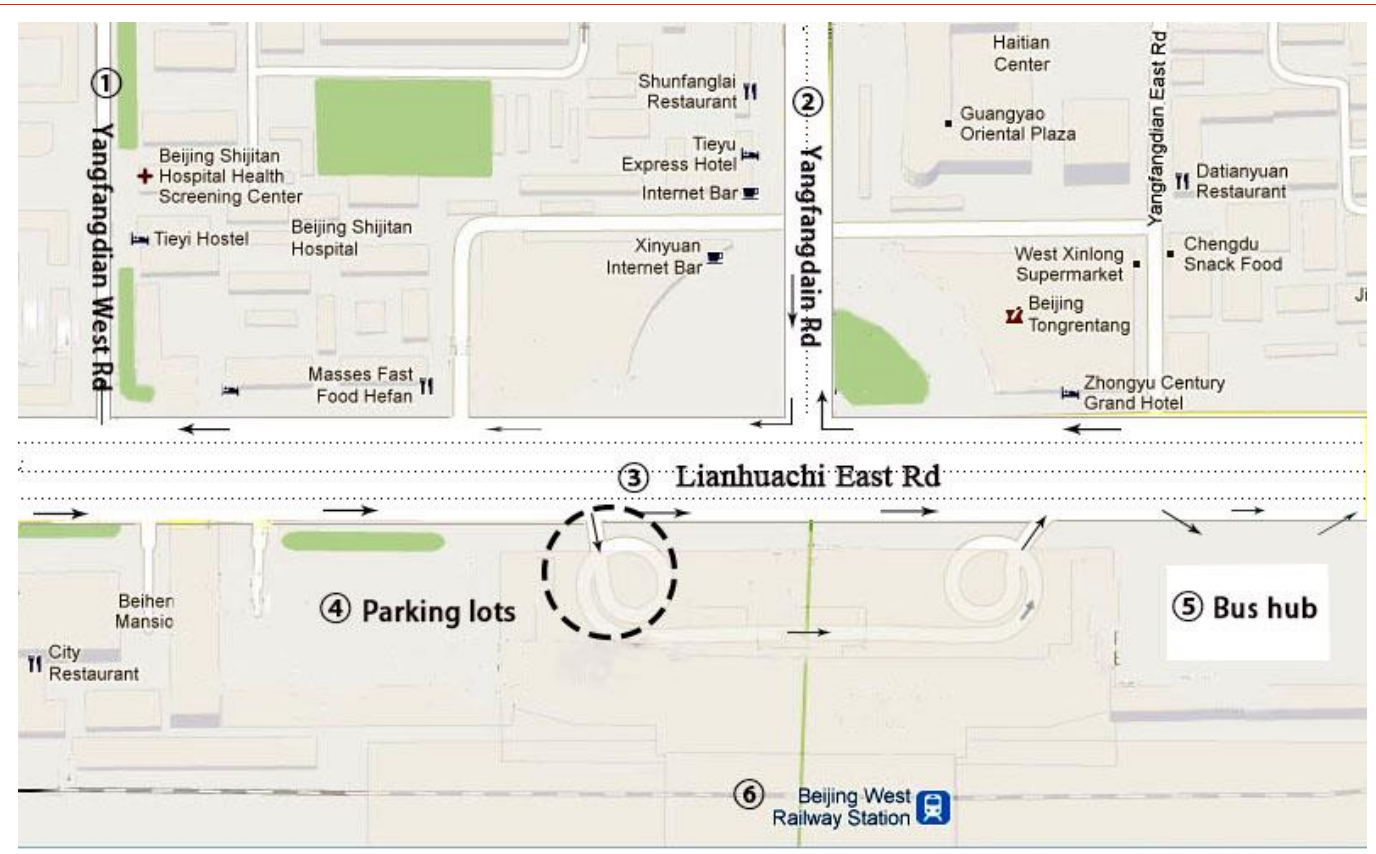

Figure 2. the 1st Congestion Point on Linhuachi East Rd.

\begin{tabular}{|r|r|r|r|}
\hline Interval Time(sec) & Travel Time(sec) & Average Delay Time (sec) & Block Time (sec) \\
\hline 900 & 35.3 & 5.4 & 0 \\
\hline 1800 & 36.6 & 6.9 & 0.1 \\
\hline 2700 & 37 & 6.2 & 0.1 \\
\hline 3600 & 35.7 & 6 & 0.1 \\
\hline 4500 & 36.1 & 5.9 & 0.1 \\
\hline 5400 & 35.8 & 6.4 & 0.1 \\
\hline 6300 & 35.9 & 5.9 & 0 \\
\hline 7200 & 36.9 & 7 & 0.1 \\
\hline 8100 & 36.2 & 5.9 & 0.1 \\
\hline 9000 & 35.7 & 5.6 & 0.1 \\
\hline 9900 & 36.5 & 7 & 0.1 \\
\hline 10800 & 36.3 & 6.3 & 0.1 \\
\hline
\end{tabular}

Table 6. Itinerary and the Delay Statistics at the $2^{\text {nd }}$ Congestion Position

As we can see from Table 6 and Table 7, vehicles' average delay time is 5-7 seconds and queue average length is 4-9 meters. Vehicles' maximum queue length may be up to 155 meters. Particularly, the bus flow and the other vehicles mix together at entrance and exit of bus hub. This situation causes blockage.

\section{Conclusions}

It can be seen from above analysis. Congestion in Lianhuachi East Rd from west to east is serious. There are two reasons which are some taxies and private cars turning to right to drop off passengers, buses entering and departing the Bus hub. 


\begin{tabular}{|c|c|c|c|}
\hline Interval Time(sec) & Queue Avg. Len (meters) & Queue Max. Len.(meters) & Delay Time (sec) \\
\hline 900 & 4 & 73 & 65 \\
\hline 1800 & 7 & 155 & 87 \\
\hline 2700 & 8 & 95 & 145 \\
\hline 3600 & 4 & 141 & 65 \\
\hline 4500 & 8 & 103 & 113 \\
\hline 5400 & 4 & 76 & 64 \\
\hline 6300 & 6 & 97 & 85 \\
\hline 7200 & 8 & 139 & 95 \\
\hline 8100 & 3 & 60 & 63 \\
\hline 9000 & 7 & 131 & 90 \\
\hline 9900 & 9 & 114 & 108 \\
\hline 10800 & 8 & 147 & 119 \\
\hline
\end{tabular}

Table 7. Vehicles Queue Statistics at the $2^{\text {nd }}$ Congestion Position

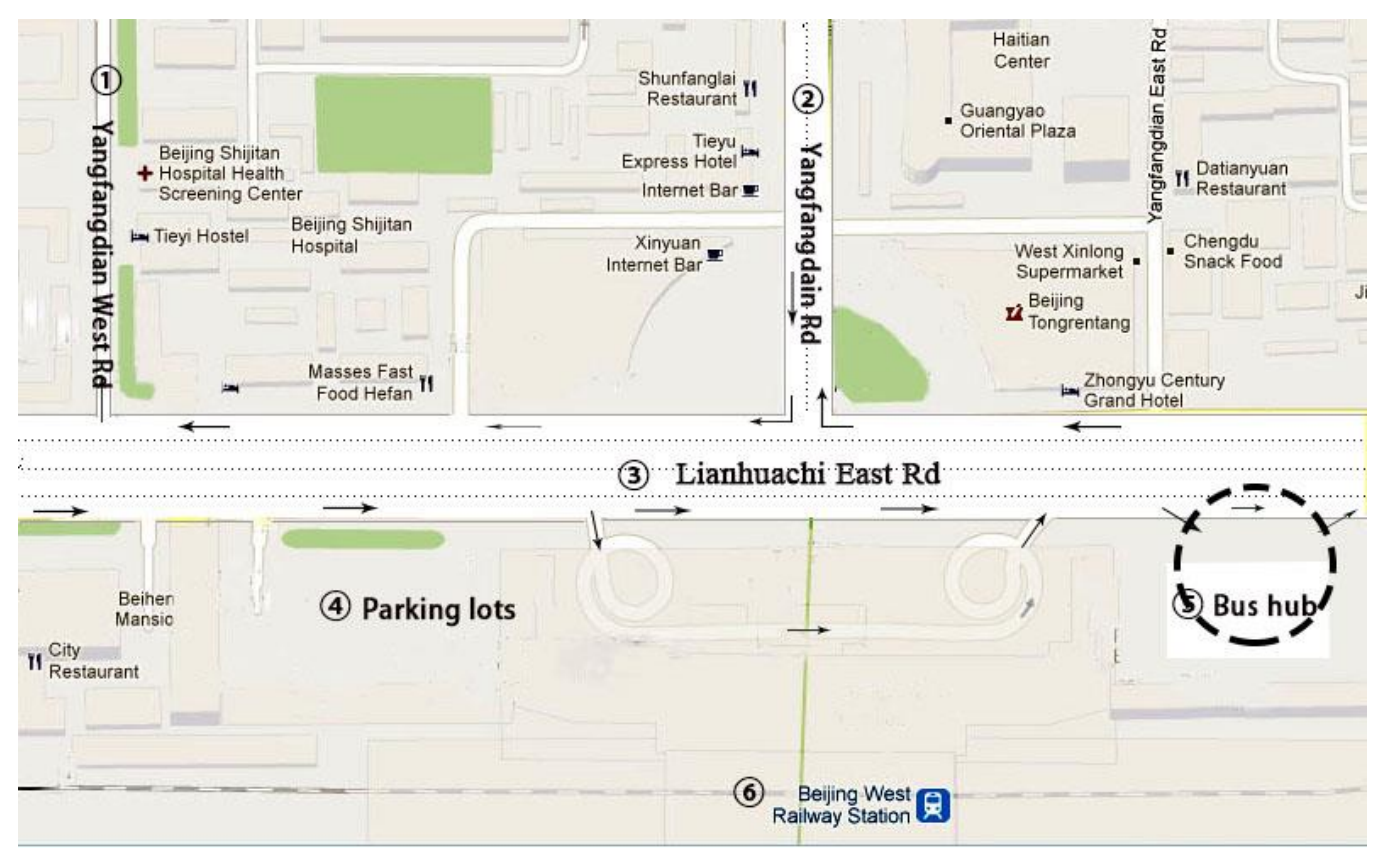

Figure 3. The $2^{\text {nd }}$ Congestion Point on Lianhuachi East Rd.

In an overall view, if we want to solve the pain of the Beijing West station congestion, the general principle is making roads smoother. Then the time of vehicles blocking on the road will be reduced, and the number of cars on the road will significantly decrease. With fewer cars on the road, road is getting clearer, which is a virtuous circle. By simulation we found that if Beijing West Railway Station south square could share some cars parking, and could cut down traffic flow to 1500 vehicles/hour, this area congestion will be improved. Meanwhile, adjusting bus interval departure time, extending to 10 minutes, could improve traffic condition as well.

\section{References}

Ahmed, K. (2011). Evaluation of low cost technique "Indirect Right Turn" to reduce congestion at urbanized signalized intersection in developing countries. Procedia Social and Behavioral Sciences, 16, 568-577. http://dx.doi.org/10.1016/j.sbspro.2011.04.477 
Bains, M.S., Ponnu, B., \& Arkatkar, S.S. (2012). Modeling of traffic flow on Indian expressways using simulation technique. Procedia Social and Behavioral Sciences, 43, 475-493. http://dx.doi.org/10.1016/j.sbspro.2012.04.121

Cunto, F., \& Saccomanno, F.F. (2008). Calibration and validation of simulation vehicle safety performance at signalized intersections. Accident Analysis \& Prevention, 40, 1171-1179. http://dx.doi.org/10.1016/j.aap.2008.01.003

Du, Z., \& Liu, B. (2012). Study on traffic flow characteristics and simulation based on the VISSIM. Applied Mechanics and Materials, 23,474-478.

Jo, Y., \& Kim, Y. (2012). Variable speed limit to improve safety near traffic congestion on urban freeways. International Journal of Fuzzy System, 14, 278-288.

Liu, P., \& Qu, X. (2012). Development of a VISSIM simulation model for U-Turns at unsignalized intersections. Journal of Transportation Engineering, 138, 1333-1339. http://dx.doi.org/10.1061/(ASCE)TE.1943-5436.0000438

Moridpour, S., \& Mazloumi, E. (2011).Enhanced evaluation of heavy vehicle lane restriction strategies in microscopic traffic simulation. Journal of Transportation Engineering-ASCE, 138, 236-242. http://dx.doi.org/10.1061/(ASCE)TE.1943-5436.0000301

Qiu, X. \& Zheng, A.X. et al. (2011). Evaluation analysis and optimization design of urban road traffic condition based on VISSIM. Applied Mechanics and Materials, 97-98, 531-534. http://dx.doi.org/10.4028/www.scientific.net/AMM.97-98.531

Stevanovic, J., \& Stevanovic, A. (2008). Stochastic optimization of traffic control and transit priority settings in VISSIM. Transportation Research Part C: Emerging Technologies, 16, 332349. http://dx.doi.org/10.1016/j.trc.2008.01.002

Tettamanti, T., \& Varga, I. (2012). Development of road traffic control by using integrated VISSIM-MATLAB simulation environment. Periodica Polytechnica-Civil Engineering, 56, 43-49. http://dx.doi.org/10.3311/pp.ci.2012-1.05

Journal of Industrial Engineering and Management, 2013 (www.jiem.org)

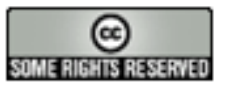

El artículo está con Reconocimiento-NoComercial 3.0 de Creative Commons. Puede copiarlo, distribuirlo y comunicarlo públicamente siempre que cite a su autor y a Intangible Capital. No lo utilice para fines comerciales. La licencia completa se puede consultar en http://creativecommons.org/licenses/by-nc/3.0/es/ 